Soledad Díaz 1

Ellen Hardy 2,3

Gloria Alvarado 4

Enrique Ezcurra 5

\title{
Acceptability of emergency contraception in Brazil, Chile, and Mexico. 1 - Perceptions of emergency oral contraceptives
}

\author{
Aceitabilidade da anticoncepção de emergência \\ no Brasil, Chile e México. 1 - Percepções sobre \\ as pílulas de anticoncepção de emergência
}

1 Instituto Chileno de Medicina Reproductiva. Casilla 96, Correo 22, Santiago, Chile.

2 Universidade Estadual de Campinas. C. P. 6181, Campinas, SP 13084-971, Brasil. hardy@unicamp.br 3 Centro de Pesquisas Materno-Infantis de Campinas. C. P. 6181, Campinas, $S P$ 13084-971, Brasil.

4 Instituto de Investigación Científica, Universidad Juárez. Apartado Postal 385, Oficina Central de Correos, Durango, Durango, México. 5 UNDP/UNFPA/WHO/World Bank Special Programme of Research, Development and Research Training in Human Reproduction. World Health Organization, CH1211 Geneva 27 Switzerland.

\begin{abstract}
This article presents the results of a study on the acceptability of emergency contraception (EC) in Brazil, Chile, and Mexico. Opinions of potential users and possible providers were obtained through discussion groups and those of authorities and policy-makers through semi-structured interviews. Most participants had a positive opinion of EC, based on the view that it can help reduce unplanned pregnancy, adolescent pregnancy, and unsafe abortion. Several interviewees felt that all women should be informed about EC, while others viewed it as a method for special situations such as rape and unprotected first sexual intercourse. Concern was expressed that its introduction might be associated with a decrease in condom use, increase in sexually transmitted diseases, and irresponsible or promiscuous sexual behavior among adolescents. The need for EC was clearly perceived by most participants, leading to the conclusion that health authorities have the responsibility of implementing programs for its introduction. Training of health care personnel should include the discussion of reproductive health problems that could be prevented by EC.
\end{abstract}

Key words Contraception; Reproductive Health; Perception

Resumo Apresentam-se opiniões de potenciais usuárias e possíveis provedores de anticoncepção de emergência (AE) no Brasil, Chile e México. As opiniões foram obtidas em grupos de discussão, e a opinião de autoridades e outras pessoas influentes por meio de entrevistas semiestruturadas. A maioria teve uma opinião positiva sobre a AE, que poderia contribuir para reduzir gravidez não planejadas, o aborto provocado e a gravidez entre adolescentes. Alguns consideraram que todas as mulheres deveriam saber sobre a AE, enquanto outros pensaram que era um método para situações especiais, tais como estupro e uma primeira relação sexual desprotegida. As preocupações foram de que sua introdução poderia estar associada à diminuição do uso do condom, aumento das doenças de transmissão sexual e comportamento sexual irresponsável de adolescentes. A necessidade da AE foi percebida pela maioria dos participantes, levando à conclusão de que as autoridades de saúde devem implementar sua introdução e treinar os profissionais de saúde, incluindo a discussão dos problemas de saúde reprodutiva que poderiam ser resolvidos pela $A E$.

Palavras-chave Anticoncepção; Saúde Reprodutiva; Percepção 


\section{Introduction}

In Latin America, as in other developing regions, two of the main reproductive health problems are unplanned pregnancy leading to unsafe abortion (Henshaw \& Morrow, 1990; Mundigo \& Indriso, 1999; Requena, 1990; Singh \& Wulf, 1994; WHO, 1993) and adolescent pregnancy (Bruno \& Bailey, 1998; Morris et al., 1988; UN, 1989). Emergency contraception (EC) could help reduce the incidence of both problems (Consortium for Emergency Contraception, 1996; WHO, 1998).

Though specific EC formulations are marketed, not all family planning programs in Latin America provide them. Nevertheless, other contraceptive methods that can be used for EC (combined oral contraceptives, levonorgestrel-only pills, and copper-releasing IUDs) are available free of cost or at low prices in many family planning clinics. Pills are also sold over the counter in some countries. However, when used, EC is generally restricted to cases of rape.

A study to assess the acceptability of EC in Latin America and to obtain information that would allow the design of appropriate strategies for its introduction was conducted in three countries, Brazil, Chile, and Mexico, with different socio-cultural and political contexts. In these countries, as in the entire region, there is limited recognition of sexual and reproductive rights, and attitudes towards sexuality are conservative, particularly in relation to adolescents. However, the power of the Catholic Church and conservative social sectors is greater in Chile and Mexico than in Brazil, while the position of the progressive Catholic sector is stronger in Brazil. Brazilian national guidelines for both family planning and care of rape victims include EC (MS, 1996); meanwhile EC was not been mentioned in official documents or health care guidelines in either Mexico or Chile.

The study providing the basis for this article focuses on previous knowledge of EC and perceptions of EC after receiving updated information on the method among potential users and providers, as well as authorities and policy - and opinion-makers. Other results are reported separately (Díaz et al., in press).

\section{Methods}

A multidisciplinary research team consisting of social scientists and biomedical professionals conducted the study, using qualitative methods (Taylor \& Bogdan, 1992). During the preparatory phase, background information was gathered on the overall socio-cultural and political context, reproductive and sexual health and rights, reproductive health services, and legal aspects relevant to the introduction of EC in each country. This information was considered essential to design the data collection instruments and interpret participants' opinions, as well as to design introductory strategies that would be sensitive to each country's context and realistic vis-à-vis local health care systems. Data were obtained by reviewing official documents, reports from other studies, academic publications, and materials from the mass media. In addition, key informants were interviewed to identify and contact potential participants, provide suggestions for improving the data collection instruments, and identify particularly sensitive issues. Research instruments were drafted and pilot-tested. Participants' opinions were collected and analyzed during the main study phase.

The following categories and sub-categories of participants were studied:

a) Potential users: Low or lower-middle-class adolescents, adolescent mothers, adult childbearing-age women, and mothers of adolescents.

b) Potential providers: Professionals working in the public sector or nongovernmental organizations (NGOs) in economically deprived areas: health service providers, schoolteachers and counselors, and women's health activists.

c) Authorities and opinion - and policy-makers: Individuals who may participate in or influence the decision-making process regarding the introduction of EC in the community: political and administrative authorities in the health, educational, and legal systems.

Potential users and providers were contacted using the chain sampling technique (Patton, 1990). Authorities and opinion - and policymakers were selected on the basis of their roles in national or local governments, professional associations, and NGOs. The opinions of authorities and influential persons, as well as of some providers in Brazil, were obtained through semi-structured (individual or collective) interviews.

- Data collection and processing: Opinions of potential users and providers were collected through discussion groups (Krueger, 1994) consisting of three sessions, held one week apart. The same five to twelve subjects, from a subcategory of participants and with similar socioeconomic characteristics, took part in a discussion group. Opinions on each of the relevant topics were prompted by direct questions 
and followed by a free discussion on the pertinent points for each particular group. An intentional effort was made to create a non-judgmental environment and to stimulate participants to pose questions and raise doubts.

Information on prior knowledge and theoretical acceptability of EC was gathered at the beginning of the first session. This was followed by a presentation on EC methods, and the initial reaction was tape-recorded. The second session explored delayed reactions and the opinion of persons with whom the participants had discussed the information received on EC. Part of the second and third sessions focused on topics related to the introduction of EC.

The opinions of authorities, opinion - and policy-makers, and some providers were obtained through semi-structured interviews (Fontana \& Frey, 1994). Written materials that described EC methods were provided in advance. Guidelines for discussion groups and interviews were developed and agreed upon by the three groups of investigators. The structures of the discussion groups and interviews were pilot-tested in each country to assess the feasibility of including the selected topics and receive suggestions to improve data collection. A total of 78 interviews (Brazil $=44$; Chile $=19$; Mexico $=15$ ) and 35 discussion groups (Brazil = 7; Chile =14; Mexico $=14$ ) were conducted and analyzed.

A common data-processing plan was also agreed upon by the three centers. Each interview and group discussion was tape-recorded. Handwritten notes taken by one of the researchers during the discussion were used as backup for the recording. Data processing included transcription of recordings, followed by an initial reading and editing (erasing names and checking the accuracy of $50 \%$ of the transcriptions against the recordings). Each transcription was then read and coded according to five thematic areas (topics): local context; prior knowledge of EC; perceptions of EC; facilitating factors and barriers to the introduction of EC; and means suggested for its introduction. Ethnograph v4.0 software was used to code the transcriptions and search for theme codes.

- Data analysis: For each country, the analysis was performed according to the following steps: (a) Descriptive analysis: individual discussion groups or interviews were coded and analyzed, describing the information according to each of the five main thematic areas; (b) Relational analysis centered on each subcategory: information collected in all interviews and discussion groups from each subcategory of participants (e.g., adolescents, childbearingage women) was analyzed jointly according to each thematic area; (c) Relational analysis centered on a thematic area: information provided by all categories of participants on a specific thematic area (e.g., perceptions of EC) was analyzed jointly; (d) Final analysis and interpretation of the results, which was done within two frameworks. The first was acceptability of EC at the social, institutional, and personal level, for which the thematic areas considered were context, knowledge, and perceptions. The second framework is not covered in this paper.

The project was approved by the appropriate Institutional Review Board (IRB) in each country and then by the Scientific Committee for Research Involving Human Subjects of the World Health Organization (WHO). Signed informed consent was obtained from all participants.

\section{Results}

\section{Prior knowledge and perceptions} concerning emergency contraception

In Brazil, some potential users and schoolteachers reported never having heard of EC, while others reported having received some information through television, written materials, or training.

"I'd never heard anything like it. I haven't the faintest idea what it could be" (Adolescent mother, Brazil).

"If you take it within 72 hours you can keep the egg from joining the sperm cell or sticking there" (Adolescent mother, Brazil).

Health care providers and opinion - and policy-makers replied that they already had some information on EC, although the accuracy of such knowledge varied.

"The day-after pill is really the same thing [as EC], because they called it the 'next day pill' and this led many people to believe that the pills could only be used during a 24-hour period, when it's actually 72 hours" (Gynecologist, Brazil).

Trainers of health care providers and some health care providers themselves had prescribed EC correctly at some time. According to them, women had reacted by asking about its efficacy.

"The last case in which I prescribed EC was last week, for an adolescent who had been raped. She was referred by the police precinct with a letter from the [female] police officer. She came with information on EC. Of course she had some doubts, like, 'Will it really work?' and regarding 
later problems that might arise, but her acceptance [of the method] was total" (Gynecologist, Brazil).

In Chile, some prior knowledge of EC was observed among health care providers and health sector authorities. Many midwives had heard about it during training activities or scientific meetings or had read about it, but they did not fully remember all the information. Some schoolteachers mentioned having heard about EC through the media or during talks by health care providers at schools. Most health activists, most potential users, and all authorities outside the health area had never heard of the method. Potential users tended to associate post-coital contraceptives with folk methods for abortion and with popular post-coital methods such as vaginal douches.

"I had never imagined that there might be some [method like this], because I thought that when it happened it happened, and you could only cross your fingers" (Adult woman, Chile).

"This method came up during the talks. But some colleagues already knew about it, and then they mentioned it and the midwife explained more" (Schoolteacher, Chile).

In Mexico, potential users and women's health activists had no prior knowledge concerning EC.

"When a woman has unprotected sexual intercourse and is afraid of getting pregnant, she finds herself in a desperate situation, because she can do nothing about it" (Member of Congress, Mexico).

Among potential providers, a few nurses had some information about post-coital contraceptive methods, but none could quote the correct use of EC pills. Only two physicians and one pharmacist had correct information. The person involved in the care of victims of sexual violence was the only provider who prescribed EC to women who had been raped less than 72 hours previously. Only a few opinion - and policy-makers had any information about the method (a journalist, a priest, and one health authority).

Mexican interviewees reported that some private clinicians prescribe high estrogen doses as post-coital contraception; other providers are known to prescribe combined pills at high doses, but not according to the recommended EC regimen. As in Chile, some participants, when asked if they knew about EC, mentioned folk methods used after unprotected intercourse or to induce menses when women experience a menstrual delay.

\section{Perceptions of EC}

\section{- Favorable perceptions}

Most participants displayed positive attitudes towards EC pills. In Brazil and Mexico, all categories of participants expressed favorable opinions and considered this method acceptable in emergency situations.

"We view [EC] as a complementary method that was needed in Mexico, because they have taken a long time to publicize it, and we hope they will soon make it available to the community" (Women's health activist, Mexico).

"I believe that this method is very positive and that it should be supported both morally and economically by the appropriate authorities" (Physician, Mexico).

In Chile, participants holding these opinions were adolescents, most adult women, women's health advocates, some health care providers, authorities on adolescents' issues, health authorities, members of Congress (from the left wing), and particularly providers of care for victims of sexual violence.

"After reading all the information, we said, 'How great! How wonderful! I would recommend it to my daughters and friends.' This is the solution to many problems in the area of contraception" (Authority, youth program, Chile).

All categories of participants felt that EC would help prevent induced abortions. The majority felt that EC is preferable to abortion and represents an alternative for women who would never go for an abortion, but who want to prevent pregnancy after unprotected intercourse.

"Of course, because the only thing that could be done to interrupt a pregnancy, for [the baby] not to be born, was to have an abortion, and now there is another option" (Adolescent mother, Chile).

In all three countries, interviewees from all categories stated that EC would help prevent the consequences of unwanted pregnancies, such as stunted life projects among adolescents, battered or abandoned children, marital conflicts, and financial problems.

"The number of unwanted children, who in the long run are problem children, and many children who are abandoned on the streets, is a huge social problem, so that justifies EC" (Schoolteacher, Chile).

"I would prefer this a thousand times rather than bringing a child into the world and not being able to give it anything, not even an education, no father, and make the child suffer" (Adolescent mother, Mexico). 
"Because I believe abortion is much more dangerous, right? Sometimes the woman dies on the table, right?" (Adult woman, Brazil).

Some felt that EC might have an educational effect, raising women's awareness concerning the risk of pregnancy and their need to use regular contraceptive methods. Others stated that EC pills have few (and minor) side effects as compared to the benefits of preventing unwanted pregnancies, and that it would immediately reduce women's fear and anxiety when faced with this possibility.

"It is good to overcome the fear and realize that one has to start using a real method, regularly" (Adolescent, Chile).

"This will sort of liberate many persons from such fear, from crying over spilled milk" (Adult woman, Chile).

Many participants from all three countries commented that pills suitable for EC are available both in public clinics and over the counter and that people already know them as regular contraceptives. They also noted that since oral contraceptives do not necessarily require a physician's prescription, EC would be easily available to women who know how to use the pills as an emergency method.

"[EC] is also good because it's easy to obtain, because it's found in any pharmacy or health center" (Adolescent mother, Chile).

In all three countries, most potential users and providers felt that women have the right to learn about and use this contraceptive alternative. Women's health activists and some professionals and authorities saw EC as a method that supports the conceptual framework of reproductive and sexual rights.

"Whether [EC] is adequate or inadequate is not an appropriate question. EC exists and should be an available option for all. For me, a new citizens' right has been launched today" (Provider of services for rape victims, Chile).

"Everything available in the state has to be made public, so this means the right to information and guaranteed rights as citizens. You can't imagine citizens without access to this" (Judge, Brazil).

\section{- Cautious opinions}

Other interviewees took a more conservative view, including many health care providers, schoolteachers, and leaders of professional health associations in Chile and a few health care providers, adult women, and mothers of adolescents in Mexico. Only a few Brazilian health care providers expressed such reservations. These interviewees viewed EC as a form of contraception for specific situations, such as rape or unprotected sexual initiation, or considered it a "lesser of two evils" compared to induced abortion and unwanted pregnancy.

"[EC] is an honorable way out, within a bad range of solutions. It is a humane way out" (Leader of a professional association, Chile).

"I believe it's good that we should manage [EC] as an instrument. But we should not do this too openly, because patients are too clever" (Midwife, Chile).

"EC frequently causes reactions like nausea, vomiting, malaise, etc., so it shouldn't be used routinely, only in extreme situations" (Gynecologist, Brazil).

\section{- Negative perceptions}

The most frequent negative opinion, held by a minority of participants in Chile and Mexico, was that EC might be a "micro-abortion" method. These participants were clearly against EC on religious grounds. Some also thought that its introduction would be associated with more health risks than benefits. In Chile, this opinion was held by a few adult women and some health care professionals and schoolteachers; and in Mexico by a few health care providers and mothers of adolescents as well as by one priest. Such strong negative opinions were not detected in Brazil.

"EC could be considered an abortifacient" (Adult woman, Mexico).

"I believe that when the egg and sperm cell join, a human being starts to exist, so in my opinion [EC] is an abortion" (Schoolteacher, Chile).

\section{- Concerns}

An issue mentioned by many interviewees from all categories in the three countries was that EC might lead to undesirable behaviors, such as a decrease in the use of regular contraceptives and/or condoms for STD/HIV prevention. This was especially emphasized in relation to adolescents, who could become more reluctant to use preventive measures on a regular basis. Even participants that were extremely enthusiastic about the method expressed these concerns.

"I have only one worry, that [EC] could turn into a routine method, meaning that [the woman] will no longer worry about family planning, and that she'll practice sexual intercourse totally unprotected" (Gynecologist, Brazil).

"This also gives them the freedom to exaggerate with sex and run the risk of catching HIV. Because there may be many adolescents who don't worry about getting AIDS, but only worry 
about not getting pregnant" (Mother of adolescent, Chile).

"This contraceptive method may suddenly contradict our messages about prevention, about condoms, in which we tell women to demand that their partners use condoms" (Community health worker, Chile).

There also were concerns about side effects, which could scare potential users, and about eventual negative effects to the fetus in case of method failure.

"The method is fine, but the side effects may not be very good for the woman" (Adult woman, Chile).

"If one takes the pills, and just the same after three days one becomes pregnant, would this harm the baby?" (Adolescent mother, Chile).

Other negative or conflicting aspects mentioned by a few participants from different categories were that there is a risk of misuse of EC, due to the spread of incorrect information, besides the possibility that it may be used as a regular contraceptive method. The concern about frequent EC was associated with the consequences that repeated use of high-dose hormones could have for women's health.

"There could be [too] frequent use of the method" (Health provider, Mexico).

"I can imagine a young girl, say 14 years old, desperate, who instead of taking four [pills] takes 12, and 12 hours later takes another 12, just to be on the safe side" (Midwife, Chile).

"A woman should not be abusing, repeating this as a regular contraceptive method. This is what we must be most careful about. We must be aware of the side effects caused by EC, and to distrust self-medication" (Public health physician, Brazil).

These concerns led some participants to feel that EC acceptability would depend on the introductory strategies. For some, the method would only be acceptable if delivered by health personnel or if the information were provided within a broader educational program on sexuality and contraception, whereby the negative health or behavioral effects could be minimized.

\section{- Changes in perceptions of EC}

In both Chile and in Mexico, changes were detected in perceptions towards EC as each discussion group evolved and participants had the chance to think about the population's reproductive health situation, particularly among low-income adolescents and women. Some participants who had expressed cautious or negative comments gradually developed a more favorable opinion. They acknowledged that this method could be an answer to real problems. The life stories disclosed by some participants (for whom EC might have changed an anguishing situation) contributed to this change.

"Something special happened to me. I kept thinking [about EC] on the bus, at home, and finally started preparing a packet with the pills to exhibit together with other methods at the clinic. At first I was scared, but I slowly changed and began to like [EC]. We can't deny it to those who need it" (Midwife, Chile).

\section{- Sharing information}

Many participants shared information from the discussion groups with family or friends and brought back comments and reactions. Most reports included positive comments, as in the following examples. Mexican adolescents who spoke to their mothers commented that the mothers had been surprised and wanted to learn more about the method. One reported her mother saying, "If I had known before, my life would have been different". Another adolescent reported that her boyfriend's reaction had been, "Sounds good, except that it's too easy to use".

In Chile, several mothers of adolescents shared the information with their sons or daughters and during the second session of the discussion group requested written materials to provide additional information. Community health workers reported that they had spread information on EC in their neighborhoods and immediately received requests to supply the pills.

\section{Potential users of EC}

All participants agreed that the method was necessary in case of rape or incest. In the three countries, most participants agreed that EC would be necessary for certain groups such as young women or young couples, as well as adult women without a stable partner or with many children. They also agreed that it was needed in some specific situations such as unprotected or unplanned intercourse, condom breakage, or partner's refusal to use a condom, as well as incorrect use of periodic abstinence or other contraceptives.

"As possible users of the EC method, I see individuals who have been victims of sexual violence, even by their husbands" (Priest, Mexico).

"[EC should be used] in what are considered exceptional situations like sexual abuse, presumed failure of a contraceptive method, or inadequate use of such a method" (Trainer of health professionals, Brazil). 
"Yes, I think that [EC] is useful anyway, because if someone does not have a stable partner and suddenly has sexual intercourse, or uses a contraceptive and that day she forgets to take the pill or the IUD has moved" (Mother of adolescents, Chile).

However, in Brazil, the use of EC by adults having unplanned sexual intercourse was not always well accepted. Interviewees felt that adults should be prepared for voluntary intercourse, even if unplanned, by having barrier contraceptives available.

"EC should be more for adolescents, because adults who already have children have a different way of thinking, and they already know how to behave in such situations, that is, whom they should consult, and what they should do" (Adolescent mother, Brazil).

Some adult women, health activists, and health care providers mentioned other circumstances in which EC would be useful: the transition between two regular contraceptive methods; during breastfeeding; or if shifting of the IUD's position were noticed. Some participants felt that EC would be useful for women in general, so it should be available to all of them. It was perceived by some as a back-up method that would be needed even if adequate policies and services were already available.

"I believe that everyone should have access to it. If the woman has had unprotected sexual intercourse, she has to know that EC exists and have access to it. I don't think there's a specific population" (Trainer of health professionals, Brazil).

"I see it as necessary even in a situation (which I'm sure will take time) in which we have adequate policies for regulating fertility and supporting sexual and reproductive rights. Even having all that, there are circumstances in which [EC] would be necessary. I think it's excellent" (Member of Congress, Chile).

\section{Adolescents' reactions}

Acceptability of the method among adolescents was particularly high, regardless of their prior sexual or reproductive experience. They felt that the method would be more useful for them than for adults, particularly for younger girls who are initiating sexual activity, since they are more exposed to unprotected intercourse.

"One never knows when one will have [sexual intercourse]: maybe at the most unexpected moment, when one has no protection" (Adolescent, Chile).

"He makes you take a drink or two, you forget to use a method, you don't plan where you're going, and by then it's too late. It's the occasion" (Adolescent mother, Mexico).

"I believe older women use theirs head more. Young people don't worry about anything. Let's keep going, it feels good, it is good, so after it happens she has to take medicine, can't sleep at night, and cries" (Adolescent mother, Brazil).

Some young women felt that EC was particularly appropriate in case of sexual intercourse with occasional partners, when it is difficult to discuss contraception or negotiate condom use. In such cases, girls would have the responsibility for preventing pregnancy and EC would empower them. On the other hand, in the case of stable relationships, several adolescents stated that it was better to use regular contraceptives than EC. One of them went as far as to say:

"Because if one is doing it, one is constantly having intercourse and worries about not getting pregnant, so it's better to always use a condom or a contraceptive and forget that this EC exists" (Adolescent mother, Chile).

There was concern about potential EC misuse or overdose, since an adolescent may despair when facing pregnancy. Based on this, they emphasized the need to disseminate accurate information.

"He wanted to have a child and I gave him one. And then I felt desperate, and if at that time I had been told, 'Fine! There's a method,' I could have used it, even more often than you're telling $m e$ " (Adolescent mother, Chile).

\section{Gender relations and EC}

Mainly young and adult women, health advocates, and schoolteachers discussed gender issues related to EC. A perceived advantage is that women can use EC without needing their partner's consent, as opposed to condoms. Since women carry the burden of pregnancy and childbearing, some participants felt that they should make the decision about EC.

"Girls get pregnant every day. Once a girl is pregnant, in most cases the boy disappears. So, I think [EC] is fantastic from a woman's point of view, at a given time when she runs the risk of an unwanted pregnancy, and she can decide, so that's freedom" (Schoolteacher, Chile).

On the other hand, many participants anticipated that young men would prefer EC to condoms, on the justification that it is used by women and does not interfere with intercourse. Adult women anticipated that women would use the method only for emergencies, while men would want them to use it more frequently.

"I think men would like it, since they don't like to use anything, and they wouldn't even 
have to use this [EC]. It would be OKfor them" (Adolescent, Chile).

Some adult women and women's health activists thought that certain men, knowing about EC, would force their partners to have unprotected intercourse or would practice more promiscuous behavior:

"I imagine that for men everything would be easier. They already resist using condoms. Just imagine if men start thinking that EC is a way to not use condoms" (Health authority, Brazil).

These were aspects of EC that participants disliked, since the method could reinforce the traditional role of women as responsible for pregnancy prevention, and could support men's irresponsible reproductive behavior.

The fact that EC requires a certain degree of maturity and decision-making ability was mentioned as a factor that could jeopardize both its acceptability and use. Participants felt that many women are not empowered to make important reproductive decisions in such a short time frame as the 72-hour window offered by EC.

"A woman with low self-esteem could be too embarrassed to ask for something like [EC], when others would realize she's in an emergency" (Community health worker, Chile).

"My impression is that the time window is too short. Of course the ideal interval would be about a week" (Mother of adolescents, Chile).

\section{EC and abortion}

There were differences, both between countries and categories of participants, in the importance ascribed to the method's mechanism of action. This was a major topic of discussion in Chile and Mexico and a less significant issue in Brazil. In general, Brazilian participants from all categories stated that EC acts by preventing pregnancy, by preventing ovulation, insemination, or implantation, and most agreed that the method does not induce abortion since it does not affect an implanted embryo.

"I don't agree that it induces abortion. I believe it actually prevents a pregnancy" (Policymaker, Brazil).

Potential users added that the association between EC and abortion would also depend on a person's moral and religious values. They also acknowledged that pregnancy varies conceptually from person to person and that some people could consider EC an abortifacient, as a few participants did. Therefore, use of the method might only be restricted among people who believe that pregnancy only begins after fertilization.
"If fertilization has occurred, any contraceptive causes an abortion. If [EC] acts on that cell that is dividing to form a new being, it's an abortifacient" (Teacher, Brazil).

In Chile and Mexico, the majority of potential providers and several potential users were truly concerned about the mechanism of action of EC. Some felt that pregnancy begins at the time of fertilization, and in Chile some participants also commented that many people erroneously believe that fertilization occurs almost immediately after coitus. Therefore, it was feared that EC would be perceived as interrupting early-stage pregnancy.

"That has always been heard, in sex education classes. I watched a video according to which life begins at the moment when the sperm cell joins the egg, at that very moment, not when it implants in the uterus" (Adolescent mother, Chile).

"Of course, from the midwife's point of view [life begins] at the time of the pronuclear fusion, immediately, since it stops being only a cell and starts becoming something else. This is somewhat similar to the woman who has an abortion" (Leader of a professional association, Chile).

Most potential providers working in government clinics in Chile and some providers in Mexico were also highly concerned about the legal implications of administering EC, if the mechanism of action were uncertain. They were afraid that the law penalizing those who perform an abortion could be applied to those who prescribe EC, if fertilization were not prevented:

"If EC can prevent pregnancy by preventing implantation it is associated with abortion, because common and penal law both specify that life begins with fertilization of the ovum" (Legislative and judiciary authority, Mexico).

One strong recommendation from several groups was that there should be more research on EC's mechanism of action, since they would feel more comfortable if they could present this as a pre-fertilization method.

"If EC is used before fertilization, it could be considered a moral flaw because of the use of contraception and not as a moral flaw because of an abortion" (Priest, Mexico).

\section{Discussion}

The study showed that EC was well-accepted by potential users and providers of the method, as well as by most authorities interviewed in Brazil, Chile, and Mexico. However, there were 
important differences between the three countries, as might be anticipated based on their different cultural and political backgrounds and value systems.

The acceptability of EC among potential users was high in the three countries, as has been shown previously among Mexican clients of family planning services (Langer et al., 1999). For all women in the study, EC was a deeply felt (and currently unmet) need. EC acceptability was apparently also high among people close to the female study participants, to whom they spoke about this method. Most health care providers and health authorities agreed to its introduction, confirming previous reports in Mexico and Brazil (Galvão et al., 1999; Langer et al., 1999). Schoolteachers, whose opinions had not been recorded in previous studies, also supported the method, although few saw themselves as potential providers.

An important finding of this study was that the availability of EC was considered part of the sexual and reproductive rights agenda and not merely a method needed for public health reasons. In the three countries, some adult women, providers, and authorities as well as all health activists held this opinion. These participants advocated for fast action by health and legal authorities in order to make EC services available to all women as soon as possible.

According to World Health Organization guidelines (WHO, 1998), emergency situations identified by participants included unplanned, unprotected intercourse, particularly among adolescents, accidents with contraceptives, and sexual violence. Some participants thought that any childbearing-age woman could eventually need EC, while others, particularly in Brazil, tended to feel that adults should be prepared to use barrier methods or regular contraception rather than EC.

As in other cultures (Ziebland et al., 1996), in these three Latin American countries we detected fear of side effects and the impact of hormones administered at higher-than-usual doses. This concern was present among potential users and providers, who tended to project contraindications against long-term use of combined oral contraceptives on EC pills. Concerns about the method's possible health impact were associated with the recommendation (expressed by most potential users and providers) that trained health care providers should administer EC. Clear messages are needed to address this concern when discussing EC pills with the general public and counseling women in clinics.

In the three countries, many participants were concerned that EC could have a negative impact on sexual and contraceptive behavior. To minimize this possibility, they suggested that the dissemination of information on EC be part of a broader sex education effort and that accurate and complete information on contraception be provided together with specific information on EC. They also suggested emphasizing: (1) EC as a method to be used only in emergency situations; (2) it benefits primarily for women who actually need it; and (3) the occasional negative health effects associated with frequent use.

Gender issues in relation to EC were discussed in the three countries. Participants, particularly potential users and health activists, saw the method as a potential way for men to pressure women in case of unplanned/undesired sexual relations and as a factor for decreased male involvement in contraception. Quick decisions and actions are required when EC is needed, meaning that women need reproductive decision-making autonomy, which is uncommon in Latin American settings. It also poses a difficulty because of limited access to the proper services.

In the three countries, participants felt that information on EC's mechanism of action is important at the personal level. They recognized that moral and religious norms and values vary among different groups and individuals. Some would consider the method unacceptable if it interfered with implantation of a fertilized egg, while others clearly felt that the method does not interrupt pregnancy, since it would not affect an implanted embryo. One strong recommendation from all groups was to conduct studies to help elucidate the exact mechanism of action of EC pills.

There were differences between countries regarding prior knowledge of EC and the method's degree of acceptance. In Brazil, participants from all categories were familiar with EC. However, as has been reported in a previous study (Glasier et al., 1996), health care providers' knowledge of EC was incomplete. We agree with these authors that health care professionals require training in order to improve women's access to the method. Meanwhile, the majority of potential users in both Chile and Mexico had no prior knowledge of EC. Incomplete knowledge was found among potential providers and policymakers, as has been previously described in Mexico (Glasier et al., 1996; Langer et al., 1999).

The differences in the countries' cultural and political contexts affected participants' perceptions of EC. In Brazil, the method was considered legitimate both socially and legal- 
ly because it is accepted in a federal law and has been regulated by the Ministry of Health. As previously reported (Glasier et al., 1996), EC's mechanism of action was not a substantial concern among providers. On the other hand, EC is not included in family planning guidelines either in Mexico or Chile, and health care providers felt a lack of official backing for prescribing the method. One major concern in these countries was the fear that EC would or could be perceived as an abortifacient, and that it would be opposed by the Catholic Church and the political right wing, which are stronger than in Brazil. The extreme situation was observed in Chile, where some health care providers and authorities were more cautious and conservative in their opinions than in Brazil and Mexico, to the extent that some providers were afraid of administrative sanctions if they prescribed EC.

According to the results of this study, EC acceptability in the general population would be greater if it were included in a broader framework, such as responsible fertility regulation and reproductive and sexual health and rights. The EC concept as a method for the prevention of induced abortion was considered essential for introductory strategies to be utilized in all three countries. In Chile, some participants even suggested that EC be presented as the "lesser of two evils" in comparison to abortion, in order to convince the conservative sector.

EC acceptability could be initiated by an awareness of extreme situations in which it is needed and the personal and public health problems it could help avoid. Acceptability may increase if the target audience is allowed more time for reflection. In this study, participants expressed more favorable opinions in the last of the three workshop sessions, having had the possibility to express doubts and concerns and hear other participants' opinions. This finding should be considered when designing training and introductory activities.

The results of this study emphasized the widespread acceptance of EC in Latin America, despite claims that this is a conservative region of the world, highly influenced by the position of the Catholic Church on such matters. The need for EC was clearly perceived by most participants, leading to the conclusion that health authorities have the responsibility to implement programs for its introduction.

\section{Acknowledgements}

We are grateful to all participants for sharing their perceptions and thoughts and to the Andrew W. Mellon Foundation for providing major financial support for this project. The study was also supported by the United Nations Development Program (UNDP)/United Nations Population Fund (UNFPA)/World Bank/ World Health Organization (WHO) Special Program of Research, Development, and Research Training in Human Reproduction and by the home institutions of the respective research teams. The authors also acknowledge the collaboration of: Maria José D. Osis; Graciana A. Duarte, Magaly Possan; Ximena Espejo; and Ana Luisa Jiménez (Brazil); Soledad Sánchez; Paulina Vidal; Gloria Salazar; Paola Díaz; and Verónica Schiappacasse (Chile); and Gerardo Cosain; Cecilia Navia; Alberto Terrones; Maria Silvia Aldaba; Sergio Estrada; and Jesús Arreola (Mexico). 


\section{References}

BRUNO, Z. V. \& BAILEY, P. E., 1998. Gravidez em adolescentes no Ceará: Maternidade ou aborto. In: Seminário: Gravidez na Adolescência (M. Vieira, M. E. L. Fernandes, P. Bailey \& A. McKay, org.), pp. 57-66, Rio de Janeiro: Associação Saúde da Família.

CONSORTIUM FOR EMERGENCY CONTRACEPTION, 1996. Emergency Contraceptive Pills. A Resource Packet for Health Care Providers and Program Managers. Washington, DC: Consortium for Emergency Contraception.

DIAZ, S.; HARDY, E.; ALVARADO, G. \& EZCURRA, E., in press. Acceptability of emergency contraception in Brazil, Chile and Mexico. 2 - Factors that may facilitate or hinder its introduction. Cadernos de Saúde Pública.

FONTANA, A. \& FREY, J. H., 1994. Interviewing: The art of science. In: Handbook of Qualitative Research (N. K. Denzin \& Y. Lincoln, ed.), pp. 361376, Thousand Oaks: Sage Publications.

GALVÃO, L.; DIAZ, J.; DIAZ, M.; OSIS, M. J.; CLARK, S. \& ELLERTSON, C., 1999. Emergency contraception: Knowledge, attitudes and practices among Brazilian obstetricians and gynaecologists. International Family Planning Perspectives, 25:168171.

GLASIER, A.; KETTING, E.; PALAN, V. T.; BROWNE, L.; KAUR, S.; BILIAN, X.; GARZA-FLORES, J.; VASQUEZ-ESTRADA, L.; DELANO, G.; FAOYE, G.; ELLERSON, C. \& ARMSTRONG, E., 1996. Case studies in emergency contraception from six countries. International Family Planning Perspectives, 22:57-61.

HENSHAW, S. K. \& MORROW, E. (ed.), 1990. Induced Abortion. A World Review. New York: Alan Guttmacher Institute.

KRUEGER, R. A., 1994. Focus Groups: A Practical Guide for Applied Research. 2nd Ed. Thousand Oaks: Sage Publications.

LANGER, A.; GARCIA-BARRIOS, C.; SCHIAVON, R.; HEIMBURGER, A.; ELUL, B.; DELGADO, S. R. \& ELLERTSON, C., 1999. Emergency contraception in Mexico City: What do health care providers and potential users know and think about it? Contraception, 60:233-241.
MS (Ministério da Saúde), 1996. Anticoncepção de emergência. In: Assistência ao Planejamento Familiar (Serviço de Assistência à Saúde da Mulher, org.), pp. 121-125, Brasília: Coordenação de Saúde da Mulher, MS.

MORRIS, L.; NUÑEZ, L.; VELASCO, A. M.; BAILEY, P.; CARDENAS, C. \& WHATLEY, A., 1988. A sexual experience and contraceptive use among young adults in Mexico City. International Family Planning Perspectives, 14:147-152.

MUNDIGO, A. I. \& INDRISO, C. (ed.), 1999. Abortion in the Developing World. New Delhi: World Health Organization/Vistaar Publications.

PATTON, M. Q., 1990. Qualitative Evaluation and Research Methods. 2nd Ed. Newbury Park: Sage Publications.

REQUENA, M. (ed.), 1990. Aborto Inducido en Chile. Santiago de Chile: Sociedad Chilena de Salud Pública/Impresora Creces Ltda.

SINGH, S. \& WULF, D., 1994. Estimated levels of induced abortion in six Latin American countries. International Family Planning Perspectives, 20:413.

TAYLOR, S. J. \& BOGDAN, R., 1992. Introduction to Qualitative Research Methods. The Search for Meaning. New York: John Wiley and Sons.

UN (United Nations), 1989. Adolescent Reproductive Behavior: Evidence from Developing Countries. Washington, DC: Department of International Economic and Social Affairs.

WHO (World Health Organization), 1993. Family and Reproductive Health. Abortion. A Tabulation of Available Data on the Frequency and Mortality of Unsafe Abortion. Geneva: WHO.

WHO (World Health Organization), 1998. Emergency Contraception: A Guide for Service Delivery. Geneva: WHO

ZIEBLAND, S.; MAXWELL, K. \& GREENHALL, E., 1996. "It's a mega dose of hormones, isn't it?" Why women may be reluctant to use emergency contraception. British Journal of Family Planning, 22:84-86

Submitted on April 4, 2003

Final version resubmitted on June 5, 2003

Approved on July 16, 2003 